\title{
CORAL REEF FISHES BIODIVERSITY IN PAHAWANG ISLAND, PESAWARAN DISTRICT LAMPUNG
}

\author{
Darma Yuliana $^{1} \cdot$ Ayu Rahmasari ${ }^{1}$. Herman Yulianto ${ }^{1}$. \\ Abdullah Aman Damai ${ }^{1}$
}

Ringkasan The components of coral reef ecosystem can be described by the unique regulation in community level. Coral reef fishes use coral reef as their habitat and they highly depend on coral reef health. Otherwise, the condition of coral reef health can be predicted by the biodiversity of coral reef fishes. The research aim was describe communities differences between two explored area in marine tourism spots in Pahawang Island. This research was conducted on November 2019 at two stations on the coral reefs ecosystem of Pahawang Island represented the two quitely different area, the marine tourism and the visitor areas. The coral reef fishes were observed by using visual census method with a Line Transect length of 30 meters and a visibility of 2.5 meters left and right of the transect. Coral reef fish community structure was measured by diversity, similarity, and dominancy indexes. A total of 1.940 coral reef fish species from 13 families were recorded. Pomacentridae is the most speciose family (1.091 spe-

1) Program Studi Sumberdaya Akuatik, Jurusan Perikanan dan Kelautan Unila, Fakultas Pertanian, Universitas Lampung

E-mail: darma.yuliana@fp.unila.ac.id cies), followed by Siganidae (308 species) and Labridae (166 species). Biodiversity of coral reef fishes at Pahawang Island showed results diversity index ( $\left.H^{\prime}\right)$ in both observation stations classified as medium with a low dominance index value $(C)$ and similarity index $(E)$ at both stations classified as high, presumably as a result of tourism activities. The diversity index at station 2 has a greater value than station 1 as a tourist area with diving and snorkeling tourism activities, at station 2 there are more types or genus of reef fish, compared to station 1.

Keywords coral reef, biodiversity, fishes, Pahawang Island

\section{PENDAHULUAN}

Terumbu karang merupakan ekosistem perairan yang memiliki produktivitas tinggi, hal inilah yang melatarbelakangi terumbu karang menjadi habitat berbagai biota laut khususnya ikan karang (Ghufran and Koordi, 2010). Ekosistem terumbu karang selain menjadi habitat berbagai jenis biota juga menjadi tempat pemijahan (spawning ground), penga- 
suhan (nursery ground), pembesaran (rearing ground), dan mencari makan ( $f e-$ eding ground) (Estradivari and Syahrir, 2009). Salah satu biota yang memegang peran penting dan berasosiasi dalam ekosistem terumbu karang adalah ikan karang.

Keanekaragaman spesies ikan karang mempunyai hubungan yang erat dengan keberadaan terumbu karang. Seluruh ikan yang hidup di terumbu karang mempunyai ketergantungan yang tinggi dalam segi perlindungan maupun makanan terhadap terumbu karang sehingga mempengaruhi jumlah individu, jumlah spesies dan komposisi jenis ikan karang (Adrim et al., 2012).

Pulau Pahawang adalah salah satu pulau yang menjadi kawasan wisata di Teluk Lampung yang memiliki objek wisata Terumbu Karang. Objek wisata terumbu karang menjadikan Pulau Pahawang ramai dikunjungi oleh wisatawan. Aktivitas wisata yang dilakukan di Pulau Pahawang antara lain aktivitas wisata snorkeling. Kegiatan snorkeling yang biasa dilakukan oleh wisatawan berdampak pada rusaknya terumbu karang di beberapa titik yang biasa dijadikan sebagai spot snorkling (Mardani et al., 2018). Kawasan wisata bahari untuk kegiatan selam dan snokeling membutuhkan data potensi ekosistem terumbu karang dan kualitas perairan yang mendukungnya. Data potensi ekosistem terumbu karang yang dikumpulkan salah satunya adalah keragaman jenis ikan karang (Yulianda, 2007).

\section{MATERI DAN METODE}

Metode penelitian menggunakan Metode sensus visual untuk penghitung- an dan monitoring ikan. Metode sensus visual digunakan untuk melihat perbedaan bentuk dari kumpulan ikan karang untuk diidentifikasi dan menggunakan kategori kelimpahan dan menghitung individu ikan karang di suatu luasan transek.

Lokasi pengambilan data komunitas ikan karang dilakukan pada 2 stasiun yang berbeda jenis kawasan. Stasiun 1 merupakan kawasan objek wisata snorkeling dan selam sedangkan Stasiun 2 merupakan kawasan dengan minim kegiatan wisata. Penentuan titik stasiun yang berbeda bertujuan untuk membandingkan komunitas ikan karang pada ekosistem terumbu karang yang dipengaruhi oleh kegiatan wisata. Penentuan titik pengambilan data dengan purposive sampling.

Pengambilan data menggunakan metode garis atau jalur transek sepanjang 30 meter yang ditarik mengikuti kontur kedalaman. Sebagai ulangan , transek dibagi menjadi 3 bagian, masingmasing transek sepanjang 10 meter dan garis imajiner sepanjang 2,5 meter ke kiri dan 2,5 meter ke kanan. Objek yang ditemukan kemudian diambil gambarnya dalam bentuk foto ataupun video. Hal tersebut untuk memudahkan identifikasi jenis ikan karang. Identifikasi ikan-ikan karang dilakukan dengan mengamati ciri-ciri morfologi ikan karang dengan buku panduan identifikasi mengacu pada Allen dkk (2003).

Indek keanekaragaman dihitung dengan persamaan Indeks keanekaragaman ShanonWiener sebagai berikut Ludwig et al. (1988),

$$
H^{\prime}=-\sum_{i=1}^{s}\left[\frac{n_{i}}{N}\right] \ln \left[\frac{n_{i}}{N}\right]
$$




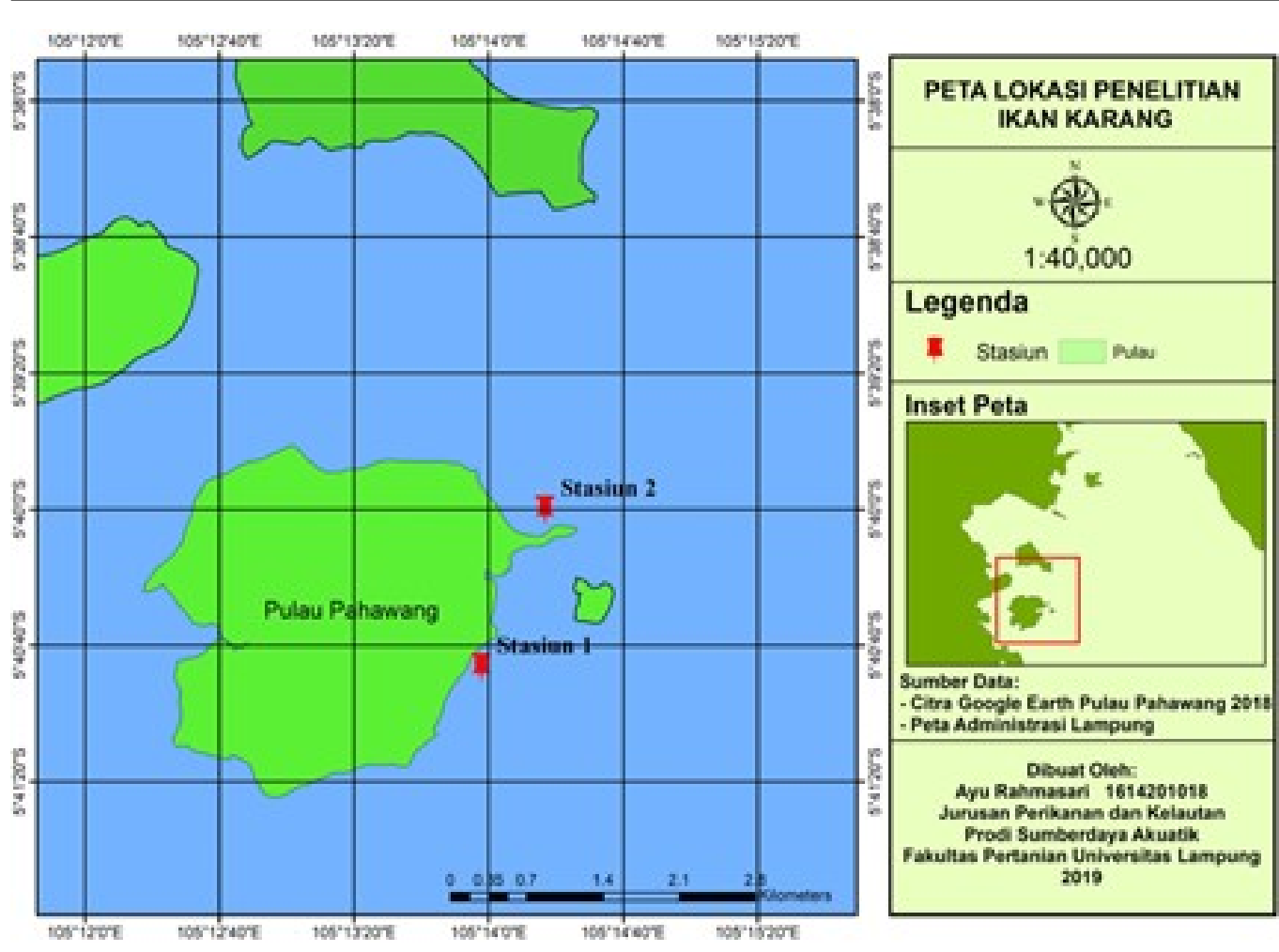

Gambar 1 Peta lokasi penelitian

dimana: H' : Indeks keanekaragaman Shannon dan Wiener; S : Jumlah spesies yang ditemukan; ni : Jumlah individu spesies ke-i; dan $\mathrm{N}$ : Jumlah individu seluruh spesies yang ditemukan dengan $\mathrm{H} \leq 2$ : Keanakeragaman rendah; $2<\mathrm{H} \leq 3$ : Keanakeragaman sedang; dan $\mathrm{H} \geq 3$ : Keanakeragaman tinggi

Indeks keseragaman jenis digunakan untuk menggambarkan penyebaran spesies yang berbeda dalam suatu komunitas. Indeks Keseragaman (E) menggambarkan ukuran jumlah individu antar spesies dalam suatu komunitas. Semakin merata penyebaran individu tiap spesies, maka keseimbangan ekosistem akan semakin meningkat. Indeks keseragaman Shanon Wiener.

$E=\frac{H^{\prime}}{H_{m a k s}}$

dimana: E' : Indeks keseragaman; H' : Indeks keanekaragaman; Hmaks : $\ln \mathrm{S}$; dan S : Jumlah spesies yang ditemukan dengan kriteria, jika $\mathrm{E}<0,4=$ Keseragaman rendah; $0,4<\mathrm{E}<0,6=$ Keseragaman sedang; dan $\mathrm{E}>0,6=$ Keseragaman tinggi

Menurut Odum (1971) Indeks Dominasi dihitung dengan persamaan

$C=\sum\left(\frac{n_{i}}{N}\right)^{2}$

dimana; C : Indeks dominasi; ni : Jumlah individu jenis ke-i; $\mathrm{N}$ : Jumlah Seluruh individu; dengan Kriteria $0,00<$ $\mathrm{C}<0,30=$ Dominasi rendah; $0,30<\mathrm{C}$ $<0,60=$ Dominasi sedang; $0,60<\mathrm{C}<$ $1,00=$ Dominasi tinggi

Parameter kualitas air diukur sebagai penunjang penelitian untuk mengetahui kondisi fisik daerah penelitian dan dilakukan pada saat berada di lokasi pengamatan atau insitu. Parameter fi- 
Tabel 1 Jenis Ikan pada Kedua Stasiun Pengamatan

\begin{tabular}{|c|c|c|c|c|}
\hline \multirow{2}{*}{ No } & \multirow{2}{*}{ Famili } & \multirow{2}{*}{ Genus } & \multicolumn{2}{|c|}{ Jumlah Individu } \\
\hline & & & Stasiun 1 & Stasiun 2 \\
\hline \multirow[t]{10}{*}{1} & Pomacentridae & Abudefduf & 269 & 80 \\
\hline & & Amblyglyphidodon & 130 & 39 \\
\hline & & Amphiprion & 31 & 4 \\
\hline & & Dischistodus & 2 & 12 \\
\hline & & Neoglyphidodon & 95 & 217 \\
\hline & & Pomacentrus & 48 & 112 \\
\hline & & Chrysiptera & 0 & 19 \\
\hline & & Dascyllus & 0 & 10 \\
\hline & & Hemiglyphidodon & 0 & 9 \\
\hline & & Plectrolyphidodon & 0 & 33 \\
\hline \multirow[t]{4}{*}{2} & Labridae & Cheilinus & 4 & 2 \\
\hline & & Haliochoeres & 9 & 11 \\
\hline & & Thalassoma & 121 & 13 \\
\hline & & Labroides & 0 & 6 \\
\hline \multirow[t]{2}{*}{3} & Scaridae & Hiposcarus & 151 & 0 \\
\hline & & Scarus & 76 & 6 \\
\hline \multirow[t]{2}{*}{4} & Serranidae & Cephalopholis & 0 & 3 \\
\hline & & Ephirephelus & 0 & 1 \\
\hline 5 & Chaetodontidae & Chaetodon & 7 & 4 \\
\hline 6 & Acanturidae & Ctenochaetus & 1 & 1 \\
\hline 7 & Lethrinidae & Lethrinus & 7 & 7 \\
\hline 8 & Nemipteridae & Pentapodus & 4 & 0 \\
\hline 9 & Pempheridae & Pempheris & 1 & 0 \\
\hline 10 & Siganidae & Siganus & 380 & 0 \\
\hline 11 & Zanclidae & Zanclus & 3 & 5 \\
\hline 12 & Apogonidae & Cheilodipterus & 0 & 6 \\
\hline 13 & Ophichthidae & Myrichthys & 0 & 1 \\
\hline
\end{tabular}

sik yang di amati, yaitu suhu, $\mathrm{pH}$, salinitas, kecerahan, kedalaman dan arus.

\section{HASIL DAN PEMBAHASAN}

Pengamatan ikan karang berdasarkan genus pada kedua stasiun diperoleh hasil sebanyak 1.940 individu yang terdiri dari 13 Famili. Pada stasiun 1 ditemukan sebanyak 18 genus ikan karang, dan stasiun 2 sebanyak 23 genus ikan karang. Jumlah keseluruhan individu pada stasiun 1 sebanyak 1.339 individu dan stasiun 2 sebanyak 601 individu.

Hasil perhitungan Indeks Shannon-Wiener diperoleh nilai keanekaragaman pada stasiun 1 sebesar 2,0841, nilai keseragaman 0,7211 dan dominasi sebesar 0,1614. Pada stasiun 2 nilai keanekaragaman
Tabel 2 Nilai H', E, dan C pada Stasiun Pengamatan

\begin{tabular}{cccc}
\hline STASIUN & H' & E & C \\
\hline 1 & 20,841 & 0,7211 & 0,1614 \\
2 & 21,345 & 0,6808 & 0,1934 \\
\hline
\end{tabular}

sebesar 2,1345, dengan nilai keseragaman sebesar 0,6808 dan dominasi sebesar 0,1934, dapat dilihat pada tabel 2. Pengukuran Parameter Fisika pada perairan seperti pada tabel 3 .

Nilai Keanekaragaman $(\mathrm{H})$ pada kedua stasiun masih tergolong sedang karena nilai $\mathrm{H}$ berkisar $2<\mathrm{H} \leq 3$. Indeks keanekaragam pada stasiun 2 memiliki nilai yang lebih besar dibanding nilai keanekaragaman stasiun 1, hal ini karena pada stasiun 2 lebih banyak dijumpai jenis atau genus ikan. Menurut Sugianti and Mujiyanto (2016) tingginya jenis ikan karang pada zona tertentu disebabkan variasi dari habitat yang terdapat terumbu karang. Indeks Keseragaman (E) pada kedua stasiun menunjukkan hasil indeks E pada kedua stasiun memilki nilai keseragaman yang tinggi karena nilai $\mathrm{E}$ lebih besar dari 0,6 , hal tersebut menunjukkan ekosistem tersebut berada pada kondisi relatif stabil yaitu jumlah individu tersebar merata di setiap spesies yang ada (Krebs et al. 1989). Sedangkan nilai Dominasi tergolong rendah pada kedua stasiun. Berdasarkan hasil perhitungan dari ketiga indeks tersebut ekosistem ikan karang Pulau Pahawang masih tergolong stabil karena hasil pengamatan yang dilakukan menunjukkan nilai keanekaragaman ikan karang di perairan Pahawang tergolong sedang dan nilai keseragaman antar spesies yang dijumpai pada stasiun pengamatan tinggi serta nilai dominasi yang rendah menunjukan tidak adanya dominasi pada . genus ikan tertentu yang tersebar di perairan Pulau Pahawang. Namun nilai Ke- 
Tabel 3 Hasil Pengukuran Fisika Air pada Stasiun Pengamatan

\begin{tabular}{ccccccc}
\hline STASIUN & $\begin{array}{c}\text { SUHU } \\
\left({ }^{\circ} \mathrm{C}\right)\end{array}$ & $\mathrm{pH}$ & $\begin{array}{c}\text { Salinitas } \\
(\% \circ)\end{array}$ & $\begin{array}{c}\text { Kecerahann } \\
(\mathrm{m})\end{array}$ & $\begin{array}{c}\text { Kedalaman } \\
(\mathrm{m})\end{array}$ & $\begin{array}{c}\text { Arus } \\
(\mathrm{m} / \mathrm{s})\end{array}$ \\
\hline 1 & 30 & $7,4-7,8$ & 27 & $2,43-3,30$ & $2,43,3,30$ & $0,057-0,072$ \\
2 & 29 & 7,7 & 26 & $2,35-2,60$ & $2,35-2-60$ & $0,014-0,015$ \\
\hline
\end{tabular}

anekaragaman di kedua stasiun yang termasuk dalam keanekaragaman sedang menandakan adanya tekanan lingkungan sedang. Allison (1996) melaporkan bahwa snorkeling dapat berkontribusi dalam kerusakan terumbu karang sebagai habitat ikan karang, Wisatawan yang melakukan kegiatan snorkeling berdiri atau menginjak koloni terumbu karang jika kedalamannya kurang dari 3 $\mathrm{m}$, maka untuk pengelolaan wisata snorkeling kedalaman yang akan mengurangi dampak kerusakan adalah $>2$ meter.

\section{SIMPULAN}

Biodiversitas ikan karang diperairan $\mathrm{Pu}-$ lau Pahawang menunjukan hasil perhitungan indeks Keanekargaman (H') pada kedua stasiun pengamatan tergolong sedang yang menandakan kedua stasiun memiliki tekanan lingkungan sedang, sedangkan nilai Dominasi (C) rendah dan Keseragaman (E) pada ekosistem di kedua stasiun tergolong tinggi. Indeks keanekaragam pada stasiun 2 memiliki nilai yang lebih besar dibanding nilai keanekaragaman stasiun 1 sebagai kawasan wisata dengan kegiatan wisata selam dan snorkeling, dilihat pada stasiun 2 lebih banyak dijumpai jenis atau genus ikan karang, dibanding stasiun 1 .

\section{Pustaka}

Adrim, M., Harahap, S. A., and Wibowo, K. (2012). Struktur komunitas ikan karang di perairan kendari (community structure of coral reef fishes at kendari waters). ILMU KELAUTAN: Indonesian Journal of Marine Sciences, 17(3):154-163.

Allison, W. (1996). Snorkeler damage to reef corals in the maldive islands. Coral Reefs, 15(4):215-218.

Estradivari, I. and Syahrir, M. (2009). Kajian struktur komunitas karang keras kepulauan seribu tahun $2005 \&$ 2007. dalam: Estradivari, e., setyawan, dan s. yusri (eds.). terumbu karang jakarta: pengamatan jangka panjang terumbu karang kepulauan seribu (2003-2007). Jakarta. Yayasan Terangi. Hlm, pages 29-39.

Ghufran, M. and Koordi, K. (2010). Ekosistem terumbu karang.

Krebs, C. J. et al. (1989). Ecological methodology. Technical report, Harper \& Row New York.

Ludwig, J. A., QUARTET, L., Reynolds, J. F., and Reynolds, J. (1988). Statistical ecology: a primer in methods and computing, volume 1. John Wiley \& Sons.

Mardani, A., Purwanti, F., and Rudiyanti, S. (2018). Strategi pengembangan ekowisata berbasis masyarakat di pulau pahawang propinsi lampung. Journal of Management of Aquatic Resources, 6(1):1-9.

Odum, E. P. (1971). Fundamentals of Ecology-3rd Edifion. WB Saunders Co., Philadelphia, 574pp.

Sugianti, Y. and Mujiyanto, M. (2016). Biodiversitas ikan karang di periaran taman nasional karimun jawa, jepara. BAWAL Widya Riset Perikanan Tangkap, 5(1):23-31.

Yulianda, F. (2007). Ekowisata bahari sebagai alternatif pemanfaatan sumberdaya pesisir berbasis konservasi.[makalah]. In $D i$ sampaikan pada Seminar Sains Departemen Manajemen Sumberdaya Perairan Fakultas Perikanan dan Ilmu Kelautan Institut Pertanian Bogor, pages 119-129.

Kontribusi: Yuliana, D: Mengambil data Lapangan, menulis manuscript; Rahmasari, A: analisis da- 
ta; Yulianto, H: Pembahasan; Damai, A, A: mengkompilasi dan mensinkronisasi 